\title{
Uma análise interseccional de gênero e raça sobre as medidas adotadas em prol da eficácia da CEDAW no Brasil ${ }^{*}$
}

\author{
Gabriela M. Kyrillos** \\ Joana Stelzer***
}

\begin{abstract}
Resumo
Partindo do conceito da interseccionalidade, a presente pesquisa analisa as ações do Estado brasileiro em prol da concretização da Convenção sobre Eliminação de Todas as Formas de Discriminação contra a Mulher (CEDAW). Tais ações foram apresentadas nos Relatórios que o Brasil enviou ao Comitê CEDAW (1984-2014). Esses documentos, organizados via análise de conteúdo, revelaram que a postura nacional tem sido de ignorar os elementos interseccionais das discriminações, mesmo quando diante de chamados específicos do Comitê CEDAW. A metodologia foi pura, dedutiva e descritiva.
\end{abstract}

Palauras-chave: Interseccionalidade, CEDAW, Gênero, Raça, Direitos Humanos.

\footnotetext{
* Recebido em 13 de dezembro de 2018, aceito em 29 de junho de 2020.

** Professora Adjunta da Universidade Federal do Rio Grande (FURG), Santa Vitória do Palmar, RS, Brasil. gabrielamkyrillos@gmail.com / https://orcid.org/0000-0001-7237-4210

*** Professora credenciada no Programa de Pós-Graduação em Direito (PPGD/CCJ) Universidade Federal de Santa Catarina (UFSC), Florianópolis, SC, Brasil. contatojoana@yahoo.com.br / https://orcid.org/0000-0002-9503-4080 
An Intersectional Analysis of Gender and Race on the Measures Adopted Under Effectiveness of CEDAW in Brazil

\section{Abstract}

Actions by the Brazilian state implement the Convention on the Elimination of All Forms of Discrimination against Women (CEDAW) are analyzed based on the concept of intersectionality. These actions were presented in reports sent by the Brazilian state to the CEDAW Committee (1984-2014). These documents, organized with content analysis, reveal that the national position has been to ignore the intersectional elements of discrimination, even when faced with specific calls from the CEDAW Committee. The methodology was pure, deductive and descriptive.

Keywords: Intersectionality, CEDAW, Gender, Race, Human Rights. 


\section{Introdução}

A presente investigação partiu do conceito de interseccionalidade cunhado pela jurista estadunidense Kimberlé Crenshaw para analisar a busca pela eficácia do disposto na Convenção sobre Eliminação de Todas as Formas de Discriminação contra a Mulher (CEDAW) ${ }^{1}$ no Brasil. Desde o primeiro momento em que a autora nomeou a interseccionalidade, ela o fez a partir de uma busca para romper com a tendência de tratar raça e gênero enquanto categorias de análise $e$ de experiências concretas mutuamente excludentes. Crenshaw entendeu que essa abordagem se perpetuava devido à forma de eixo-único que dominava a produção das leis contra a discriminação racial $e$ as teorias feministas $e$ antirracistas. A autora sugeria que esse modo de eixo-único invisibilizava as mulheres não-brancas na conceitualização, identificação e na remediação quanto à discriminação de raça e gênero, sendo limitadas pelas experiências dos outros membros mais privilegiados do grupo, criando análises distorcidas sobre racismo e discriminação de gênero (Crenshaw, 1989).

Neste artigo abandonou-se a forma de eixo-único que predomina nas análises acerca do acesso das mulheres aos Direitos Humanos. A partir da interseccionalidade, adotou-se, portanto, as categorias de gênero e raça como fundamentais para averiguar os limites da concretização do disposto na CEDAW no Brasil. A CEDAW é o principal documento internacional sobre Direitos Humanos das Mulheres e possui um Comitê permanente dedicado a analisar os relatórios periódicos que os Estados-parte se comprometem a enviar, expondo suas ações em prol da concretização do disposto na Convenção.

O Brasil - como signatário da CEDAW desde 1984 - efetivou o envio periódico de relatórios ao Comitê, desde 2002 - quando realizou a remessa dos cinco primeiros relatórios de uma única vez. Desde então, o país encaminhou regularmente seus relatórios no período analisado por essa pesquisa (1984-2014). Dessa forma, foram analisados os cinco primeiros relatórios do Estado brasileiro para o Comitê CEDAW remetidos em 2002 (referente aos anos: 1985, 1989, 1993, 1997 e 2001), o VI Relatório de 2005 e o VII Relatório de 2010. Realizou-se, portanto, a análise de todos os sete relatórios que o Estado enviou para o Comitê CEDAW durante as três primeiras décadas após a ratificação da Convenção pelo Brasil (de 1984 a 2014).

Em que pese o compromisso do Estado brasileiro com a CEDAW, o problema dessa investigação consistiu no seguinte: de que modo ocorreu a busca pela eficácia da CEDAW no Brasil a partir de uma preocupação interseccional de raça e gênero? A hipótese central sustenta que raça $e$ gênero, enquanto categorias fundamentais para tornar eficaz os direitos e as garantias previstas na CEDAW, tornaram-se progressivamente ausentes dos relatórios, fato que se interliga à fragilidade das respectivas políticas públicas também em ritmo de desaceleração de conquistas.

Em razão disso, foram analisados documentos de maneira detalhada, no anseio de construir uma síntese do que foi encontrado sobre a atuação do Estado brasileiro. O objetivo geral consistiu em avaliar os documentos no intuito de construir um diagnóstico das ações realizadas pelo Estado brasileiro para a concretização da CEDAW, tendo como lente a necessidade de criação de protocolos interpretativos que tomem em consideração a discriminação interseccional. Assim, enquanto objetivos específicos, buscou-se: descrever o tema da interseccionalidade no próprio Comitê CEDAW, posto que é o responsável pelas diretrizes axiológicas de interpretação e eficácia da CEDAW; identificar a lógica e os possíveis contrassensos que acompanham a discussão relativa ao conceito de interseccionalidade; $e$, verificar se a aplicação da CEDAW no Brasil ocorre de forma interseccional.

De modo complementar, com o propósito de identificar as preocupações existentes para além dos órgãos estatais, buscou-se constatar se há a presença de preocupações interseccionais de raça e gênero no relatório alternativo produzido pela sociedade civil em 2007, conhecido como Relatório Sombra ou Contra-Informe da Sociedade Civil para o Comitê CEDAW. Também foram elementos de estudo as Observações Finais do Comitê CEDAW ao Estado brasileiro (2003; 2007; 2012).

Compõem o marco teórico do presente escrito as pesquisas desenvolvidas por Kimberlé Crenshaw (1989; 1991; 1997), Patricia Hill Collins e Sirma Bilge (2016), Meghan Campbell (2015)

\footnotetext{
${ }^{1}$ CEDAW, sigla, em ingles, de Convention on the Elimination of All Forms of Discrimination Against Women.
} 
Sueli Carneiro (1995; 2003), Lélia Gonzalez (1984) e Nilma Lino Gomes (2005). O presente trabalho é justificado pelas manifestas desigualdades sociais e econômicas ainda persistentes quando se considera, em particular, o acesso a direitos por mulheres negras e indígenas no Brasil.

Quanto à metodologia utilizada para realizar a análise desses documentos, valorizou-se a Análise de Conteúdo de Laurence Bardin (1977), conforme detalhado especificamente na parte 3 do artigo. No que diz respeito à natureza, trata-se de pesquisa pura ${ }^{2}$ e quanto à abordagem do problema classifica-se como qualitativa. Em relação ao método de abordagem, a pesquisa é dedutiva, pois a partir das premissas estabelecidas forneceram-se razões suficientes a favor da conclusão, especialmente no que se refere ao fato de o Estado brasileiro não conseguir incorporar satisfatoriamente preocupações e medidas interseccionais de raça e gênero. Em relação aos fins foi utilizado o método descritivo, já que houve forte propósito em apresentar aspectos destacados dos Relatórios CEDAW e contrastar com os Relatórios brasileiros. Os meios foram documentais e bibliográficos, com destaque para os documentos CEDAW e do Estado brasileiro.

\section{Os avanços interseccionais no campo dos direitos humanos internacionais - a importância do Comitê CEDAW}

O Comitê CEDAW ocupou papel de grande relevância na presente pesquisa na medida em que é ele o responsável (conforme disposto no art. 17 da CEDAW) por analisar os relatórios enviados pelo Estado brasileiro. Além disso, o Comitê ocupa um lugar central no entendimento contemporâneo dos objetivos e propósitos da CEDAW. Dessa forma, para analisar a aplicação da CEDAW no Brasil é relevante iniciar por considerar a forma como a interseccionalidade surgiu no próprio Comitê CEDAW, posto que é ele quem dá as diretrizes para a interpretação e eficácia da Convenção.

Antes de abordar a interseccionalidade a partir dos documentos disponibilizados pelo Comitê é válido, ainda que de forma bastante resumida, conceituar o que se compreende por interseccionalidade na presente pesquisa.

Parte-se das conceituações de Kimberlé Crenshaw ${ }^{3}$ que, em um primeiro momento, apresenta a interseccionalidade como metáfora (Crenshaw, 1989) e em seguida como ferramenta analítica capaz de contribuir para a solução de problemas muitas vezes invisibilizados (Crenshaw, 1991). Ocasionalmente, a metáfora criada por Crenshaw é mais conhecida que o próprio conteúdo completo de seu texto. Nela, a autora apresenta o cruzamento das ruas de trânsito enquanto analogia para pensar sobre a forma das diferentes categorias de discriminação se entrecruzarem. Nessa metáfora, Crenshaw (1989) revela a interseccionalidade como ferramenta para compreender melhor a situação das pessoas que se encontram no centro desse cruzamento, no qual há tráfego indo e vindo de diferentes direções.

Em um texto de 1997, a autora afirma que a "Interseccionalidade é ao mesmo tempo um conceito fundamentalmente provisório e ilustrativo" (Crenshaw, 1997:248). Ou seja, depois de seus primeiros escritos sobre interseccionalidade, Crenshaw concilia o caráter de metáfora com a ideia de um conceito analítico provisório. Interseccionalidade é, portanto, "[...] uma categoria transitória que liga os conceitos correntes com suas consequências políticas [...]" (Crenshaw, 1997:248). Nesse sentido, categorias consagradas, como gênero ${ }^{4}$ e raça, ${ }^{5}$ só podem ser compreendidas em sua

\footnotetext{
2 A pesquisa pura representa um tipo de investigação que reúne estudos com a finalidade de preencher uma lacuna no conhecimento, visando ao progresso da ciência (Gil, 2019).

3 Vale destacar que não se ignora que a interseccionalidade possui importantes raízes anteriores ao momento em que foi nomeada por Kimberlé Crenshaw, tal qual analisado por Collins e Bilge (2016). Sobre isso, recomenda-se o texto "Uma Análise Crítica sobre os Antecedentes da Interseccionalidade" de Gabriela Kyrillos (2020).

4 Gênero, de acordo com a historiadora Joan Scott "É uma maneira de se referir às origens exclusivamente sociais das identidades subjetivas dos homens e das mulheres. O gênero é, segundo essa definição, uma categoria social imposta sobre um corpo sexuado. [...] O uso do 'gênero' coloca a ênfase sobre todo um sistema de relações que pode incluir o sexo, mas que não é diretamente determinado pelo sexo nem determina diretamente a sexualidade" (Scott, 1995:7).

${ }^{5} \mathrm{O}$ conceito de raça não deve ser entendido como foi utilizado do século XVI ao XIX, para reproduzir ideias da colonialidade moderna que compreendia a existência de uma hierarquia racial. Nessa pesquisa, assim como ocorre quando o conceito raça é utilizado pelos Movimentos Negros e por algumas e alguns intelectuais das Ciências Sociais na atualidade, está se partindo de uma nova interpretação, tal qual apresentada por Nilma Lino Gomes (2005:45), que se
} 
abrangência concreta e política a partir de visão interseccional, capaz de identificar os momentos nos quais as interações dessas categorias geram experiências concretas diferenciadas, em particular, em processos discriminatórios comumente ignorados e invisibilizados.

Partindo dessa breve fundamentação acerca da interseccionalidade, passa-se a investigar de que forma esse conceito tem sido incorporado no campo internacional dos Direitos Humanos, em particular pelo Comitê CEDAW. Para isso, a pesquisa desenvolvida por Meghan Campbell (2015) igualmente se tornou fundamental. Com o propósito de demonstrar o quão diferenciada tem sido a interpretação da CEDAW - por meio de seu Comitê - sobre as discriminações baseadas no gênero $e$ em demais marcadores sociais, a autora demonstra como outros Tratados da Organização das Nações Unidas (ONU) possuem "abordagem mais tradicional" caracterizada por enumerar diversas categorias diferentes de discriminação.

Campbell (2015:484), nesse desiderato, faz menção específica ao Pacto Internacional sobre Direitos Civis e Políticos e ao Pacto Internacional sobre Direitos Econômicos, Sociais e Culturais. Em ambos é possível identificar essa estrutura que a expert considerou como sendo uma 'abordagem mais tradicional' sobre as diferenças. Dessa forma, taisPactos utilizam uma 'abordagem tradicional' para se aproximar do tema da discriminação com base em mais de uma categoria de análise.

De acordo com Campbell (2015:485), existem duas formas de abordar as discriminações interseccionais. A primeira delas é a já mencionada enumeração de distintas categorias. A segunda forma de abordar essas discriminações pode ser identificada no texto da Convenção Internacional sobre a Eliminação de Todas as Formas de Discriminação Racial (ICERD) e da Convenção sobre os Direitos da Pessoa com Deficiência (CRPD), bem como nas Recomendações Gerais de seus respectivos Comitês. Nos textos dessas Convenções não há, portanto, previsão explícita sobre a interação de elementos identitários elencados. Contudo, a CRPD reconhece em seu artigo $6^{\circ}$ (Organização das Nações Unidas, 2007) que as mulheres e meninas com deficiência enfrentam "múltiplas formas de discriminação". De modo semelhante, também prevê em seu artigo $7^{\circ}$ que sejam adotadas medidas específicas para assegurar os Direitos Humanos das crianças com deficiência (Organização das Nações Unidas, 2007). Coerente com o conteúdo da Convenção, o Comitê CRPD reafirmou em suas recomendações gerais que as mulheres com deficiência estão sujeitas a múltiplas e interseccionais formas de discriminação baseadas no gênero e na deficiência (Campbell, 2015:485).

O Comitê da Convenção Internacional sobre a Eliminação de Todas as Formas de Discriminação Racial (CERD), por sua vez, possui duas Recomendações Gerais muito relevantes que abordam a discriminação interseccional. Conforme destacado por Meghan Campbell (2015:487), em tais recomendações o Comitê abordou a relação da discriminação racial com a de gênero (Recomendação Geral $n^{\circ} 25$ ) e a relação entre raça e direitos de cidadania (Recomendação Geral $\left.n^{\circ} 30\right)$.

Após tais reflexões sobre as abordagens da discriminação nos Tratados da ONU, Campbell (2015:486) conclui que é possível identificar avanços nas abordagens sobre os distintos grupos e suas múltiplas experiências de discriminação interseccional no que costuma ser classificado como instrumentos de alcance específico de Direitos Humanos Internacionais - sendo a CEDAW um deles.

Assim, Campbell (2015:486) realiza sua análise da CEDAW e de seu Comitê. A autora parte do pressuposto de que o escopo da CEDAW de eliminar todas as formas de discriminação contra as mulheres e promover a igualdade de gênero necessariamente inclui o compromisso de considerar a discriminação interseccional - já que, sem isso, torna-se impossível incluir todas as mulheres dentro desses princípios norteadores da CEDAW. Para Campbell (2015), o que a CEDAW e o seu Comitê

baseia na dimensão social e política do conceito de raça. A utilização do termo raça é uma escolha política adequada para o Brasil posto que a forma como se dá a discriminação racial no país, desenvolve-se não apenas a partir de elementos da identidade étnica de determinado grupo, mas também em razão dos aspectos físicos possíveis de ser observados na estética corporal dos membros desse grupo (Gomes, 2005:45). Ou seja, "raça ainda é o termo que consegue dar a dimensão mais próxima da verdadeira discriminação contra os negros, ou melhor, do que é o racismo que afeta as pessoas negras da nossa sociedade" (Gomes, 2005:45). 
têm feito é assumir uma postura mais fluida acerca das discriminações que as mulheres sofrem, o que não significa dizer que se adota uma preocupação exclusivamente de gênero.

Em sua pesquisa, Campbell (2015:483) identificou alguns avanços na inclusão da interseccionalidade nas análises e propostas do Comitê CEDAW. A autora afirma que os textos da CEDAW e de seu Comitê foram capazes de compreender de modo sofisticado a discriminação interseccional, razão pela qual, as discriminações com base nas diferenças de sexo e de gênero não são analisadas de modo isolado das demais formas de discriminação (Campbell, 2015:490).

Tal posicionamento pode parecer incoerente quando se tem em consideração que a única menção no texto da CEDAW à pobreza e à etnia está em seu preâmbulo. Campbell (2015:486) não ignora que existem críticas que afirmam que a CEDAW falhou ao não reconhecer a complexidade da experiência das práticas discriminatórias que as mulheres sofrem, contudo, a autora considera que essa interpretação é uma leitura equivocada da Convenção, pois apesar de não haver menção explícita à discriminação interseccional, o texto da CEDAW está permeado por considerações a respeito das diferentes experiências vividas pelas mulheres. Posicionamento, aliás, reforçado ao longo dos anos pelo Comitê CEDAW.

Campbell (2015) também destacou que as recomendações do Comitê CEDAW têm reforçado a importância de aspectos inicialmente citados apenas no preâmbulo da Convenção (como pobreza e raça), bem como da desigualdade interseccional, para que se construam estratégias de acesso de todas as mulheres aos Direitos Humanos contidos na Convenção. Para a autora, o Comitê CEDAW em mais de uma ocasião "[...] tem observado que as mulheres de grupos étnicos minoritários, idosas, deficientes e migrantes, mulheres encarceradas e mulheres e meninas que vivem nas ruas são particularmente vulneráveis às desigualdades e discriminações" (Campbell, 2015:480) ${ }^{6}$. Campbell (2015:483) considera que a CEDAW está transcendendo às persistentes descontinuidades entre a teoria interseccional $e$ as legislações $e$ políticas voltadas para a superação das discriminações.

[...] o Comitê CEDAW, semelhante ao Comitê CRC entende que a discriminação interseccional não se limita a motivos baseados em status, mas também a problemas transversais que as mulheres experimentam, como a dissolução das relações familiares. Existem vários outros elementos identitários que são especificamente protegidos na CEDAW. O artigo 4 e o artigo 11 oferecem uma proteção específica às mulheres com base na gravidez e na maternidade. $\mathrm{O}$ artigo 9 proíbe a discriminação com base na nacionalidade e o artigo 14 protege as mulheres rurais $e$ garante-lhes o direito de participar e se beneficiar do desenvolvimento rural $e$ do acesso aos cuidados de saúde, transporte, habitação, segurança social, eletricidade, água, comunicações e saneamento (Campbell, 2015:487).

A autora acredita que a postura da CEDAW e de seu Comitê podem servir como modelo, na medida em que são pioneiros ao assumir uma forma fluida de considerar a discriminação interseccional que integrou de maneira mais eficaz a teoria da interseccionalidade e a prática jurídico-política (Campbell, 2015:483). Nesse sentido, para Campbell não há um conceito de interseccionalidade completamente desenvolvido na CEDAW, no entanto

[...] uma análise textual mais profunda revela que existe um compromisso implícito para abordar todas as formas de opressão e discriminação experienciadas pelas mulheres, incluindo a discriminação interseccional (Campbell, 2015:488).

A perspectiva de Campbell é a de que a CEDAW toma a experiência das mulheres como base fundamental de suas preocupações e, ao invés de adotar uma abordagem baseada em categorias monolíticas de discriminação e enumerá-las, "[...] adota uma concepção fluida e expansiva das mulheres que permite uma apreciação das várias combinações e permutações de discriminação que as mulheres experienciam" (Campbell, 2015:488).

\footnotetext{
${ }^{6}$ Essa e outras citações diretas relativas ao texto de Meghan Campbell (2015) são traduções livres realizadas pelas autoras. O mesmo ocorre com o texto de Crenshaw (1997). Ambos são originalmente em inglês e sem tradução para o português até o momento.
} 
Uma leitura intencional da CEDAW é a chave para desbloquear o compromisso do tratado de remediar a discriminação interseccional. O objetivo da CEDAW é eliminar a discriminação e alcançar a igualdade para que as mulheres possam desfrutar e exercer seus direitos humanos $e$ liberdade fundamental em todos as esferas da vida (Artigo 1, CEDAW, Comitê CEDAW, Recomendação Geral n $\left.{ }^{\circ} 28, \S 4\right)$. O compromisso da CEDAW de condenar a discriminação contra as mulheres em todas as suas formas (Artigo 2, CEDAW) fornece uma base textual firme que exige que o Estado aprecie e responda por todas as identidades, experiências e fatores que contribuem para a discriminação e desigualdade de gênero. O Comitê considerou que estas disposições "estabelecem uma obrigação global para eliminar a discriminação em todas as suas formas" (Comitê CEDAW, Recomendação Geral $\mathrm{n}^{\circ} 19, \S 10$ ). Isso inclui inerentemente a discriminação interseccional, pois é uma forma de discriminação única. Se as mulheres experimentam uma discriminação enraizada em seu sexo e/ou gênero e isso cruza com outros aspectos de sua identidade ou experiências e resulta em uma negação de direitos humanos, é possível e deve ser abordada através da CEDAW (Campbell, 2015:488).

A pesquisa de Campbell (2015) sobre a CEDAW e o seu Comitê, além de ser inovadora, apresentou informações e percepções até então ignoradas quando se analisava esse documento internacional tão relevante no campo dos Direitos Humanos das Mulheres. Reforçou-se o entendimento de que não é preciso uma lista de categorias monolíticas enumeradas de forma aditiva para que se construam visões e estratégias efetivamente interseccionais. Ao mesmo tempo, é possível que se questione, desde já, os limites da mera presença de categorias enumeradas quando se trata de buscar uma aplicação interseccional dos Direitos Humanos.

Campbell (2015:498) destaca, ainda, as limitações na inclusão da interseccionalidade nas Recomendações do Comitê CEDAW, em razão de suas relevantes inconsistências. Para demonstrar como se apresentam tais inconsistências na abordagem do Comitê CEDAW, Campbell utiliza o caso concreto de Alyne da Silvia Pimentel Teixeira, uma brasileira negra e pobre que vivia na área rural.

Poucos dias antes de dar à luz, ela frequentou um centro de saúde local reclamando de náuseas severas e dor abdominal. Dois dias depois, ela deu à luz a um feto natimorto. Ela foi submetida a uma cirurgia para remover a placenta 14 horas após o parto, mas sua condição piorou. $\mathrm{O}$ centro de saúde contatou os hospitais públicos e privados com instalações superiores para tratála. Um hospital privado tinha espaço, mas recusou-se a enviar sua única ambulância para transportá-la. Teixeira "esperou em condições críticas durante oito horas para ser transportada para o hospital". No hospital, foi deixada sem vigilância no corredor durante 21 horas até falecer. Ela morreu devido a uma hemorragia digestiva, que foi o resultado do parto de um feto morto. Sua mãe apresentou uma Comunicação Individual e o Comitê da CEDAW concluiu que Teixeira foi discriminada em razão de ser "afrodescendente e em razão de sua situação socioeconômica" (Campbell, 2015:488).

Fica notório, nesse caso, como o Comitê foi sensível às discriminações sofridas por Alyne Pimentel e como elas atuaram de forma múltipla e capaz de produzir um processo de discriminação interseccional. Em publicação recente sobre o caso, as pesquisadoras CintiaCatoia, Fabiana Severi e Inara Firmino destacaram a importância desse entendimento do Comitê CEDAW e como essa se tornou "[...] uma das principais jurisprudências de Direitos Humanos das Mulheres que oferece parâmetros para abordagem interseccional da violência contra as mulheres" (Catoia et al., 2020:2).

Contudo, Campbell identificou certa insegurança do Comitê a respeito do que fazer com tal conclusão:

Na decisão substantiva, não há uma avaliação detalhada de como suas múltiplas identidades contribuíram para a morte dela [Alyne Pimentel] e não há referência à discriminação interseccional na recomendação do Comitê CEDAW (Campbell, 2015:488).

Ao aplicar essa nova abordagem, o Comitê CEDAW faz repetidas referências à discriminação interseccional e chama a atenção dos Estados para o fato de que as mulheres de raça ou etnia minoritária vivem desproporcionalmente na pobreza. No entanto, às vezes, o Comitê CEDAW é inconsistente e desatento para a desvantagem interseccional que afeta as mulheres. 
Compreender a interseccionalidade como componente da igualdade na CEDAW fornece as ferramentas para garantir uma abordagem mais abrangente (Campbell, 2015:481).

O entendimento de Campbell de que se deve interpretar a CEDAW e as Recomendações do seu Comitê tomando em consideração a discriminação interseccional é coerente com a proposta contida na teoria da interseccionalidade, em especial, nos escritos de KimberléCrenshaw (2002:), para quem é preciso superar a recorrente interpretação dos Tratados Internacionais sobre Direitos Humanos e legislações internas que se limitam a considerar apenas um único eixo de poder. Crenshaw (2002:181-182) critica tais formas de interpretação, pois acredita que, muitas vezes, existem "[...] possibilidades explícitas nas convenções, leis e declarações, cujo intento é proteger os indivíduos da negação de direitos baseada na raça e no gênero"; o que pode acabar não ocorrendo integralmente, por não ser considerada a discriminação interseccional tal qual proposto por Campbell.

De fato, Crenshaw já alerta há mais tempo que os direitos garantidos na CEDAW abarcam todas as experiências das mulheres no que diz respeito à discriminação de gênero e, portanto, também pode ser entendido que faz parte de suas preocupações as discriminações sofridas pelas mulheres não-brancas, por ser uma discriminação interseccional de raça e gênero. É por essa razão que Crenshaw compreende que nem sempre é necessária nova formulação de leis e tratados, mas, que "[...] seria útil que se desenvolvessem protocolos interpretativos a fim de romper com os limites das interpretações e práticas existentes, os quais reduzem os direitos das vítimas de subordinação interseccional" (Crenshaw, 2002:182). Com isso, a presente pesquisa se insere em já existente rol de trabalhos que compreendem a interseccionalidade como aspecto fundamental do campo dos Direitos Humanos internacionais, tal qual apresentado por Crenshaw (2002); Campbell (2015); Catoia et al. (2020); Collins e Bilge (2016); dentre outras. Sob tal ótica, Crenshaw entende como de fato relevante o surgimento de novos protocolos interpretativos, esses sim fundamentais para que tais textos jurídicos se tornem mais amplos e eficazes.

É válido destacar que, ao contrário do texto da Convenção, as Recomendações Gerais ou Específicas não são vinculativas para os Estados. Apesar disso, Campbell (2015) não ignora o aumento da visibilidade do trabalho realizado pelo Comitê CEDAW, bem como, da ampliação do reconhecimento da legitimidade das interpretações que o Comitê proporciona. Além disso, a autora demonstra de forma explícita algumas das diversas ocasiões em que o Comitê CEDAW atuou de forma a considerar a discriminação interseccional (Campbell, 2015:495).

Campbell reforça que as Observações Finais do Comitê CEDAW são fonte legítima de interpretação da Convenção no campo do Direito Internacional dos direitos humanos.Além disso, o documento tem se mostrado coerente com as dificuldades contemporâneas do acesso a direitos enfrentado pelas mulheres, em particular não-brancas e pobres. É possível perceber, em síntese, o potencial da interseccionalidade enquanto categoria na busca por novas formas de lidar com as barreiras enfrentadas quando se trata do acesso aos Direitos Humanos.

A presença da discriminação interseccional - enquanto preocupação do Comitê CEDAW dialoga com o escopo da presente investigação de analisar em que medida a interseccionalidade tem se feito presente na atuação do Estado brasileiro quando da busca por efetivar a Convenção. Reconhecendo que preocupações interseccionais têm perpassado a interpretação do Comitê CEDAW sobre a Convenção, cabe considerar se o Brasil tem incorporado esse documento e, em que medida e de que forma, a questão da interseccionalidade de raça e gênero emerge na aplicação da CEDAW.

\section{Diagnóstico sobre as limitações na aplicabilidade da CEDAW no Brasil a partir de uma perspectiva interseccional de raça e gênero}

Um dos objetivos centrais dopresente artigoé averiguar de que modo tem ocorrida a busca pela eficácia da CEDAW no Brasil a partir de uma preocupação interseccional de raça e gênero. Para isso recorre-se à análise de conteúdo nos moldes estabelecidos por Laurence Bardin (1977). Trata-se de pesquisa qualitativa por meio de análise categorial possível a partir da construção de índices via categorização léxica (Bardin, 1977). No caso da análise de tais relatórios, o critério léxico 
de categorização partiu do objetivo da pesquisa e do referencial teórico. Ou seja, foi uma "classificação das palavras segundo o seu sentido, com emparelhamento dos sinônimos e dos sentidos próximos" (Bardin, 1977:118).

No que concerne aos sete relatórios produzidos pelo Estado brasileiro é importante destacar que se partiu de dois objetivos centrais: (1) Averiguar se o Estado brasileiro tem incorporado (e em caso afirmativo, de que forma) a interseccionalidade de raça e gênero em seus relatos sobre a implementação da CEDAW; e (2) Identificar se está ocorrendo, tal qual indicado nos estudos anteriormente analisados ${ }^{7}$, um esvaziamento da interseccionalidade quando de sua utilização pelo Brasil para apresentar suas ações frente ao Comitê CEDAW.

O relatório Sombra também foi estudado qualitativamente via Análise de Conteúdo e por meio dos índices anteriormente citados. Ele surgiu em 2007 e era referente ao VI relatório estatal. Tal documento deve ser considerado de forma complementar, para que se possa ter visão mais ampla sobre a realidade brasileira acerca do acesso de todas as mulheres aos Direitos Humanos, bem como, considerar se há (e de que forma) preocupação interseccional de raça e gênero no País no âmbito da sociedade civil.

A escolha por uma análise categorial do corpus a partir dos índices construídos observou não apenas elementos quantitativos, pois tomou em consideração a totalidade do texto (Bardin, 1977:37). Para ir além da questão estatística, realizou-se a leitura e a releitura dos documentos, procedendo-se à análise de contingência na qual o contexto, no qual está inserido o índice, é muito importante (Bardin, 1977). Somente dessa forma tornou-se possível inferir não apenas se conceitos como interseccionalidade e raça fazem parte do repertório utilizado pelo Estado brasileiro na busca pela efetivação da CEDAW no País, como também de que forma esses conceitos estão sendo empregados.

Em razão disso, após a análise dos documentos detalhados anteriormente, na presente seção, buscou-se construir uma síntese do que foi ali encontrado sobre a atuação do Estado brasileiro.

Trata-se de assumir uma estratégia de investigação semelhante à realizada por Campbell (2015) e sugerida por Crenshaw (2002) quando se faz, intencionalmente, a leitura dos elementos interseccionais presentes na CEDAW e no Comitê CEDAW, indo além da mera presença (ou ausência) de termos como interseccionalidade.

A presente pesquisa constatou que inúmeras vezes o Comitê demandou do Estado brasileiro que considerasse as questões interseccionais de raça e gênero, algo coerente com as constatações de Campbell (2015) em sua pesquisa. Vale destacar, como exemplo, algumas das observações realizadas pelo Comitê CEDAW, em 2012, nas suas Observações Finais referentes às análises do VII Relatório brasileiro e às respostas apresentadas pelo Estado-parte.

A título exemplificativo é possível destacar quando o Comitê apresenta sua preocupação com a situação das pessoas trabalhadoras domésticas, em especial das mulheres negras e meninas "[...] que, muitas vezes, sofrem de múltiplas formas de discriminação" (Organização das Nações Unidas, 2012:3), tendo, ademais, recomendado que o Brasil "adote um quadro regulamentar legislativo para proteger os direitos dos(as) trabalhadores(as) domésticos(as), em particular mulheres afrodescendentes" (Organização das Nações Unidas, 2012:3) e que

[...] tome as medidas adequadas para assegurar a igualdade efetiva para as mulheres trabalhadoras domésticas, bem como medidas destinadas a eliminar as múltiplas formas de discriminação contra as mulheres afrodescendentes trabalhadoras domésticas (Organização das Nações Unidas, 2012:3).

\footnotetext{
7 As pesquisas anteriores sobre a interseccionalidade a que se está referindo nesse trecho são as realizadas por Marília Ortiz (2013) e Emanuela Lombardo e Mieke Verloo (2009). Na pesquisa de Marília Ortiz (2013) é possível perceber de que modo a interseccionalidade tem se aproximado do campo das políticas públicas no Brasil, em especial a partir das Secretarias que lidavam com conceitos como raça e gênero de modo transversal. A conclusão apresentada pela autora é de que predomina no Brasil apenas uma superinclusão de termos e a permanência de estrutura pensada para lidar com categorias monolíticas de discriminação. Tal constatação é semelhante à conclusão do estudo de Emanuela Lombardo e Mieke Verloo (2009) sobre a possível institucionalização da interseccionalidade na União Europeia. Nessa pesquisa, as autoras concluíram que os marcos legais da União Europeia não estão de fato usando a interseccionalidade em sua complexa e transformadora concepção, mas sim, justapondo categorias de desigualdades sem, de fato, intersectá-las.
} 
Outro momento em que se identifica, nas Observações Finais, preocupação interseccional de raça e gênero ocorre quando o Comitê menciona as ações de caráter temporário de promoção da igualdade material. Ao reconhecer a atuação do Estado brasileiro na criação de cotas raciais para o acesso de pessoas negras e indígenas ao ensino formal, o Comitê ressalta que ainda que tais ações possam beneficiar as mulheres não há avaliação específica sobre isso, de modo que não é possível estimar o impacto para as mulheres, preocupando-se também "[...] com a ineficiência aparente no uso de medidas especiais temporárias para diferentes grupos de mulheres" (Organização das Nações Unidas, 2012:4). Assim sendo, o Comitê recomenda que o Estado brasileiro atue por meio de medidas adicionais com o propósito de ampliar o entendimento acerca do conceito de medidas especiais temporárias enquanto estratégia indispensável para a concretização da igualdade "em especial para as mulheres com deficiência, afrodescendentes, indígenas e rurais, em áreas como a participação política, saúde, educação e emprego" (Organização das Nações Unidas, 2012:4).

Ao abordar o tema da violência contra as mulheres, o Comitê CEDAW também destacou que é preciso reforçar as ações do judiciário em prol do acesso das mulheres à Justiça, destacando mais uma vez que se considere especialmente as mulheres pertencentes aos "grupos desfavorecidos" (Organização das Nações Unidas, 2012:5). De forma similar, sugeriu que o Estado brasileiro adote medidas especiais temporárias para ampliar a participação das mulheres na esfera pública e política do País, em especial "[...] no que diz respeito aos grupos de mulheres em desvantagem, como as afrodescendentes, indígenas e mulheres com deficiência" (Organização das Nações Unidas, 2012:6).

No que diz respeito à educação, o Comitê também expressou preocupação "com as persistentes desigualdades no acesso à educação para mulheres e meninas em razão de sua raça, etnia e situação socioeconômica" (Organização das Nações Unidas, 2012:7). Por essa razão, o Comitê faz um chamado para que o Brasil "Tome medidas para superar as desigualdades no acesso à educação para meninas e mulheres com base em sua raça, etnia e situação socioeconômica, para assegurar-lhes o acesso de fato igual a todos os níveis de ensino;" (Organização das Nações Unidas, 2012:7). Novamente, é possível identificar que o Comitê CEDAW compreende que são necessárias ações que considerem não apenas o gênero, mas também outras categorias como a raça, para que seja possível superar as desigualdades materiais.

De forma semelhante, o Comitê - ao abordar o tema do acesso ao emprego - reconhece que a categoria raça é altamente relevante no caso das mulheres brasileiras, pois "Preocupa o fato de que a diferença salarial entre homens e mulheres flutue entre $17 \%$ e $40 \%$, dependendo da raça, etnia e educação das mulheres" (Organização das Nações Unidas, 2012:8).

No documento, ainda, há expressa menção às mulheres indígenas, quando se aborda o tema das mulheres encarceradas, destacando-se preocupação com a falta de serviços de tradução nesse âmbito (Organização das Nações Unidas, 2012:9). Por essa razão, quando demanda que o Estado brasileiro atue para facilitar o acesso à Justiça e providenciar julgamento justo para as mulheres $e$ meninas em situação prisional, salienta que devem ser consideradas especialmente as necessidades das mulheres indígenas (Organização das Nações Unidas, 2012:10).

Outra preocupação e recomendação que se repete nas Observações Finais é a ênfase do Comitê sobre a necessidade de que se elaborem dados acerca das mulheres brasileiras e da necessidade de desagregação por categorias como sexo, raça, condição socioeconômica, dentre outras. O Comitê destaca que é fundamental ter tais dados atualizados para a consecução de avaliações precisas sobre a situação das mulheres brasileiras, de forma a determinar se elas sofrem discriminações e formular políticas para a sua superação (Organização das Nações Unidas, 2012:10).

Assim sendo, é possível observar que há uma demanda internacional para o Estado brasileiro adotar medidas pautadas em visão interseccional de raça e gênero quando da busca pela eficácia da CEDAW. A presença de índices - tal qual apresentado anteriormente - foi um primeiro modo de aproximação com os documentos analisados. Os índices foram divididos em três categorias de sentido, quais sejam: 
Quadro 1: Grupo de índices

\begin{tabular}{|l|l|}
\hline A & interseccionalidade / inter-seccionalidade / intersecção \\
\hline B & raça / etnia / cor / racial \\
\hline C & $\begin{array}{l}\text { negra(s) / negro(s) / afrodescendente(s) / índia(o)(s) / indígena(s) / não-branca(s) / } \\
\text { não-branco(s) / branca(s) / branco(s) / quilombola(s) / quilombo }\end{array}$ \\
\hline
\end{tabular}

Fonte: Primária.

Com tais índices foi possível uma aproximação quantitativa da abordagem adotada pelo Estado brasileiro. Assim sendo, constataram-se mudanças quantitativas em suas presenças/ausências ao longo dos Relatórios. É inegável que o lapso temporal para o envio do primeiro Relatório brasileiro - que resultou em uma compilação de cinco relatórios enviados de uma só vez - é uma questão relevante, pois se relaciona com a postura do Estado brasileiro frente aos Direitos Humanos internacionais em contexto de ditatura militar e, posteriormente, de redemocratização. Nossa pesquisa considerou três planos de análise: a) os cinco primeiros relatórios, abordados como um único bloco de análise na medida em que foram assim apresentados pelo Brasil (contendo 259 páginas); b) o Relatório de 2005 (com 109 páginas); e, o Relatório de 2010 (com 70 páginas). Com tais estruturações foi possível construir a tabela abaixo que demonstra como esses índices foram cada vez menos utilizados pelo Estado brasileiro.

Tabela 1: Presença quantitativa dos grupos de índices em todos os relatórios brasileiros enviados ao Comitê CEDAW

\begin{tabular}{|l|c|c|c|}
\hline $\begin{array}{c}\text { Relatórios do Brasil para o } \\
\text { Comitê CEDAW }\end{array}$ & $\begin{array}{c}\text { Todas as citações dos } \\
\text { índices do grupo A }\end{array}$ & $\begin{array}{c}\text { Toda as citações dos } \\
\text { índices do grupo B }\end{array}$ & $\begin{array}{c}\text { Todas as citações dos } \\
\text { índices do grupo C }\end{array}$ \\
\hline 2002 - I ao V Relatório & 2 & 137 & 191 \\
\hline 2005 - VI Relatório & 0 & 86 & 121 \\
\hline 2010 - VII Relatório & 0 & 61 & 64 \\
\hline
\end{tabular}

Fonte: Primária, elaborada a partir dos sete primeiros Relatórios que o Estado brasileiro enviou ao Comitê CEDAW.

A junção dos cinco primeiros relatórios tende a dificultar, em alguma medida, a análise quantitativa. Mas, é válido destacar os indícios de algumas tendências a partir do VI e do VII Relatório. Uma dessas tendências é a diminuição no número de páginas em aproximadamente 35\% entre o relatório de 2005 e o de 2010. Outra propensão, possivelmente mais relevante, é aquela que demonstra a diminuição no número de vezes em que aparecem os índices acima detalhados, posto que - se há uma redução no número de páginas e uma redução no número de menções aos índices - fica notória uma grande redução da abordagem de temas relacionados às questões raciais que perpassam o acesso das mulheres aos direitos contidos na CEDAW no Brasil.

Ainda que seja preciso considerar outros elementos, além da presença/ausência desses índices de sentido, parece alarmante o fato de que foram sendo cada vez menos utilizados pelo Estado brasileiro, tanto para abordar suas ações em prol da concretização da CEDAW quanto para realizar um diagnóstico da situação atual das mulheres brasileiras. Tais dados contribuem para o entendimento de que entre 2002 e 2010 passa a ocorrer uma espécie de apagamento na utilização de marcadores sociais relacionados com a categoria raça (conforme é possível observar o grupo $\mathrm{C}$ ). Isso, por si só, não indica a ausência de preocupações interseccionais. Contudo, ao considerar também a absoluta ausência de menção aos índices do grupo A nos relatórios de 2005 e 2010, é possível observar indícios de uma tendência de redução dos debates sobre as questões de raça no que diz respeito à eficácia da CEDAW no Brasil. Esses dados são coerentes, portanto, com os constantes chamamentos que o Estado brasileiro tem sofrido por parte do Comitê CEDAW, demandando do País mais dados e medidas que considerem outras categorias analíticas, que não somente gênero. 
Além do corpo do texto dos Relatórios, cujo conteúdo foi sistematizado na tabela anterior, existem inúmeras tabelas e gráficos que abordam temas conexos. Considerando que o Relatório de 2010 é o que apresenta o mais baixo número de citações aos índices pesquisados, mas que é, contudo, o que mais apresenta tabelas e gráficos, realizou-se detida análise com o propósito de sistematizar quantas análises gráficas levavam em consideração, de alguma forma, a relação de gênero e raça no Brasil, o que resultou na síntese abaixo.

Tabela 2: Presença quantitativa de índices raciais em todos os relatórios brasileiros enviados ao Comitê CEDAW.

\begin{tabular}{|l|c|c|c|c|c|}
\hline $\begin{array}{c}\text { Relatórios do Brasil para o } \\
\text { Comitê CEDAW }\end{array}$ & $\begin{array}{c}\text { Número total de } \\
\text { tabelas e gráficos com } \\
\text { dados sobre a } \\
\text { realidade brasileira }\end{array}$ & $\begin{array}{c}\text { Tabelas ou } \\
\text { gráficos que } \\
\text { abordem } \\
\text { raça/etnia }\end{array}$ & $\begin{array}{c}\text { Sobre } \\
\text { Negra(s) }\end{array}$ & $\begin{array}{c}\text { Sobre } \\
\text { indígena(s) }\end{array}$ & $\begin{array}{c}\text { Sobre "Não- } \\
\text { branca(o)(s)" } \\
\text { e "outro(s)" }\end{array}$ \\
\hline 2002 - I ao V Relatório & 38 & 7 & 4 & 1 & 3 \\
\hline 2005 - VI Relatório & 20 & 10 & 10 & 0 & 1 \\
\hline 2010 - VII Relatório & 41 & 3 & 3 & 0 & 0 \\
\hline
\end{tabular}

Fonte:Primária, elaborada a partir dos sete primeiros Relatórios que o Estado brasileiro enviou ao Comitê CEDAW, especialmente quanto à análise gráfica.

A tabela acima reafirma que o Relatório de 2010 é o que menos aborda as questões raciais. No Relatório de 2005, 50\% das tabelas e gráficos apresentavam alguma informação considerando as mulheres negras, enquanto no Relatório de 2010 esse número reduziu para 7,3\% - chegando a $0 \%$ quando se tratava das mulheres indígenas. Esses dados parecem incoerentes quando se considera as Recomendações do Comitê CEDAW para o Estado. Desde a primeira avaliação do Comitê CEDAW sobre os cinco primeiros relatórios enviados pelo Estado brasileiro, o Comitê vem demonstrando preocupação com a especificidade das desigualdades que sofrem as mulheres negras $e$ indígenas no Brasil.

De fato, a primeira recomendação do Comitê em seu documento para o Brasil em 2003 afirmava preocupação com

[...] a existência de uma grande defasagem entre as garantias constitucionais de igualdade entre mulheres e homens e a situação atual de fato (de facto) social, econômica, cultural e política das mulheres no país, a qual se amplia no que se refere às mulheres afrodescendentes e indígenas (Organização das Nações Unidas, 2003).

Essa recomendação é um chamado para que o Brasil atue de modo a considerar as discriminações interseccionais de raça e gênero quando da elaboração de estratégias que visem à eficácia da CEDAW. Ainda assim, esse chamado de 2003 não se viu refletido nas ações expostas nos Relatórios de 2005 e, especialmente, no Relatório de 2010.

Campbell (2015), em sua já mencionada pesquisa, também considera que o Comitê CEDAW adotou sua forma fluida de considerar a interseccionalidade ao enviar suas Recomendações para o Estado brasileiro. Nessa pesquisa, ao analisar de forma mais detida todos os documentos relacionados com o País, resta confirmada essa preocupação do Comitê CEDAW. Não há dúvidas, portanto, que o Brasil recebeu diretamente instruções que demonstram que se faz necessário compreender a CEDAW e as recomendações de seu Comitê a partir de perspectiva interseccional.

Além disso, com a apresentação do Relatório Sombra em 2007, o Estado brasileiro teve acesso mais uma vez à visão que considerava como indispensável a inclusão de outros marcadores sociais, para além do gênero. Em síntese, o Relatório Sombra (Coletivo Feminino Plural, 2007) apresentou preocupações que iam muito além da categoria gênero para pensar a situação das brasileiras quanto ao acesso aos Direitos Humanos, conforme é possível observar logo no início do documento: 
O Contra-Informe da Sociedade Civil traz questionamentos que expõem a fragilidade da situação das mulheres no país, agravada quando se trata de afrodescendentes, indígenas, residentes em zonas rurais, moradoras urbanas de menor poder aquisitivo, prostitutas, portadoras de necessidades especiais, presidiárias, chefes de família, lésbicas, mulheres vivendo com HIV/Aids, enfim, de meninas, de jovens ou idosas e de outros grupos de mulheres marginalizadas ou socialmente excluídas. Em vista disso, o texto evidencia a persistência de muitas desigualdades de gênero [...] Desigualdades que se acentuam devido ao pertencimento étnico, geracional, regional ou socioeconômico, e dificultam o avanço das mulheres na sociedade brasileira (Coletivo Feminino Plural, 2007:4).

O Relatório Sombra, ou Contra-Informe da Sociedade Civil, bem como as Recomendações Gerais e Observações Finais do Comitê CEDAW para o Brasil são fontes relevantes para se pensar a eficácia dos preceitos contidos na CEDAW no País. Ambos são coerentes com a preocupação de Crenshaw (2002:174), de que "Onde os contornos específicos da discriminação de gênero não são bem compreendidos, as intervenções para tratar de abusos aos Direitos Humanos das Mulheres serão provavelmente menos efetivas.". Não há como desconsiderar que o Estado brasileiro tem tido acesso, no campo político dos movimentos sociais e na esfera jurídica internacional dos direitos humanos, tanto às recomendações quanto à necessidade de se considerar as discriminações interseccionais como elementos que contribuem fortemente para a perpetuação da distância entre a igualdade formal e a igualdade material no Brasil.

Apesar disso, predomina nos Relatórios brasileiros o que Campbell (2015:485) conceituou como 'abordagem tradicional das diferenças'. Enquanto o Comitê CEDAW assume uma visão mais fluida das discriminações, o Estado brasileiro adota uma postura na qual o gênero é a principal categoria de análise e que, em contextos pontuais e de forma não regular, irá interagir com outras. Por essa razão, é comum encontrar nos três blocos de Relatórios, textos que citam diversas categorias de análise sem, contudo, aprofundar nenhuma delas ou suas interrelações. Esse tipo de postura constrói uma frágil (quando não inexistente) relação entre os termos, o que acaba contribuindo para que não sejam seriamente considerados no momento de elaboração das políticas públicas e legislações. Emerge inconteste que esse é um dos fatores que contribui para que as desigualdades materiais se perpetuem.

Por essa razão, as análises teóricas sobre a efetivação dos Direitos Humanos das Mulheres no Brasil e as estratégias políticas e jurídicas adotadas pelo Estado não devem ignorar a complexidade da situação vivenciada pelas mulheres brasileiras que estão, em sua maioria, lidando com questões estruturais de discriminações interseccionais de raça e gênero ${ }^{8}$. A importância de tal preocupação, de acordo com Crenshaw, reside no fato de que "[...] seria útil que aqueles que esperam articular e/ou responder às necessidades das mulheres marginalizadas antecipassem as várias formas pelas quais as vulnerabilidades de raça e de gênero podem se entrecruzar" (Crenshaw, 2002:174). Com efeito, trata-se de algo que é visível quando se considera, por exemplo, a cegueira do Estado brasileiro sobre as mulheres negras e sobre o acesso à educação de ensino superior.

Diante da preocupação do Comitê CEDAW com as mulheres negras e indígenas e seu acesso ao ensino superior - já que as cotas que existiam no Brasil até o momento do envio de seu relatório eram raciais e sociais, mas não em razão do sexo ou gênero - o Estado brasileiro afirmou que cotas por sexo seriam desnecessárias na medida em que a maior parte das pessoas que têm acesso ao ensino superior são mulheres, desconsiderando, completamente, a situação específica das mulheres negras e indígenas em um País no qual somente $24,1 \%$ das vagas em instituições de ensino superior são ocupadas por pessoas negras (tal qual apresentado no próprio Relatório brasileiro). Ou seja, quando o Estado brasileiro considera que as mulheres têm acesso igualitário ao ensino superior no Brasil, o faz por meio do apagamento das condições de acesso e da permanência que

\footnotetext{
8 Merece destaque o livro de Carla Akotirene (2018) que muito bem aborda o tema da interseccionalidade a partir do Brasil. Nessa obra, a autora ressalta como a preocupação com os aspectos da desigualdade analisada de forma interseccional envolve compreender os marcadores sociais como aspectos estruturais da sociedade. Por essa razão, Akotirene reforça que "A interseccionalidade impede aforismos matemáticos hierarquizantes ou comparativos. Em vez de somar identidades, analisa-se quais condições estruturais atravessam corpos, quais posicionalidades reorientam significados subjetivos desses corpos [...]" (Akotirene, 2018:39).
} 
são dadas às mulheres negras e indígenas, algo que torna notória a priorização da categoria gênero em detrimento da raça. Tal circunstância contribui de forma insuspeitada para perpetuar a marginalização das mulheres negras e indígenas.

No Relatório brasileiro de 2005, por sua vez, predominou uma perspectiva de transversalização do gênero e, com menor visibilidade, também da raça. ${ }^{9}$ Contudo, vale destacar aqui que diversas vezes nem mesmo a transversalidade foi adequadamente considerada, o que reforça mais uma vez que a mera presença de termos não implica a adoção de medidas $e$ estratégias que o incorporem.

No Relatório de 2010, o menor de todos, utiliza-se com frequência a expressão intersetorialidade que parece demonstrar esforço por parte do Governo de que seus diferentes órgãos atuem de modo coerente em prol da concretização dos Direitos Humanos no País. Com o desmantelamento das Secretarias e órgãos do Governo Federal que atuavam em áreas essenciais da promoção dos Direitos Humanos - tal qual a Secretaria de Política para as Mulheres (SPI) e a Secretaria de Promoção da Igualdade Racial (SEPPIR) - a perspectiva de que temas como Direitos Humanos, sexismo, racismo, lgbtfobia e tantos outros, sejam considerados no momento de atuação dos órgãos estatais é cada vez mais remota.

Torna-se ainda mais necessário que se construam estratégias que priorizem a maior eficiência dos investimentos em políticas públicas. Dessa forma, o entendimento de Crenshaw (2012) - de que não necessariamente é preciso que se construam novas legislações (ou políticas) para que se tome seriamente em consideração a discriminação interseccional - é um chamado para a construção de novos e contextualizados protocolos interpretativos sobre documentos jurídicos já existentes.

De acordo com Crenshaw, igualmente é preciso que se amplie o rol de legitimados para construir tais protocolos não se limitando apenas ao trabalho realizado pelos diversos órgãos de vigilância de Tratados como o Comitê CEDAW e o CERD, mas, incluindo também "[...] as atividades da comunidade mais ampla de Direitos Humanos" (Crenshaw, 2002:174). A autora afirma que, de igual modo, deve contribuir para tais protocolos a atuação de ONGs e outras instituições que investigam as

[...] implicações de gênero do racismo, da xenofobia e de outras formas de intolerância e de maior conscientização quanto às implicações de raça, etnia, cor e outros fatores que contribuem para uma combinação de abusos dos Direitos Humanos que mulheres e, por vezes, homens enfrentam (Crenshaw, 2002:174).

Collins e Bilge (2016), a partir do convite feito a Crenshaw pelo Comitê de organização da Conferência Mundial contra o Racismo, Discriminação Racial, Xenofobia e Intolerâncias Correlatas, ocorrido em Durban, África do Sul, em 2001, identificaram que a partir de seu position paper, as referências ao conceito da interseccionalidade (mesmo que com outras nomenclaturas) tornou-se cada vez mais comum no âmbito internacional dos Direitos Humanos. Sendo assim, quando essa pesquisa revela que existe na CEDAW e nas recomendações diretas e gerais do seu Comitê elementos suficientes para que o Brasil adote postura interseccional de raça e gênero na busca pela concretização de Direitos Humanos, verifica-se verdadeira contribuição para a construção de protocolos interpretativos. A pesquisa acadêmica é, portanto, um dos caminhos pelos quais tais protocolos podem e devem ser criados para que o arcabouço jurídico de proteção dos Direitos

\footnotetext{
9 Vale destacar que transversalidade não é sinônimo de interseccionalidade. A transversalidade "Parte da consideração de que as ações, as políticas e os programas têm resultados diferentes para homens e mulheres. Por esse motivo, a perspectiva das mulheres deve ser considerada no desenho, na implementação, no surgimento e na avaliação das políticas e dos programas em todos os âmbitos, com o objetivo de que homens e mulheres sejam beneficiados igualmente e que a desigualdade não se perpetue. Incluindo atividades específicas e ações positivas por que as posições de largada para homens e mulheres não são iguais" (Molina, 2012:205). Tal conceito contribuiu para que a pauta de gênero fosse incluída de modo transversal em outras discussões sobre direitos humanos - como no campo do direito ao trabalho e do direito à saúde. Como destacado por Carmen Molina (2012:205), os dois conceitos - interseccionalidade e transversalidade - são ferramentas complementares na busca pela superação das desigualdades de gênero, na medida em que a interseccionalidade contribui para tornar visíveis as diferentes realidades nas quais se encontram as mulheres, podendo assim, melhorar a própria estratégia política.
} 
Humanos das Mulheres seja utilizado da forma mais eficaz possível, apesar de quaisquer retrocessos que o cenário político apresente.

\section{Conclusão}

O que se revelou com a análise dos documentos enviado pelo Comitê CEDAW ao Brasil, bem como por meio de uma leitura intencional da CEDAW, é que não se faz necessária a ratificação de algum outro Tratado Internacional que verse especificamente sobre a interseccionalidade. O que sim é necessário é que se leiam tais recomendações e documentos internacionais com olhar atento às discriminações interseccionais.

Em sentido oposto às necessidades, em regra, a postura do Estado brasileiro tem sido de ignorar os elementos interseccionais das discriminações, mesmo quando diante de chamados específicos do Comitê CEDAW, por meio dos questionamentos ou das Observações Finais do Comitê para o Brasil.

Assim sendo, ao retomar as duas questões feitas inicialmente nesse texto é possível chegar a duas conclusões importantes. Primeiro, o Estado brasileiro nas suas ações de 1984 a 2014 descritas ao Comitê CEDAW, não tem conseguido incorporar satisfatoriamente preocupações e medidas interseccionais de raça e gênero. A utilização de categorias como raça ou etnia nos relatórios aparece constantemente de forma secundária e sua presença foi sendo ainda mais reduzida com o passar dos anos, apesar das demandas do Comitê CEDAW terem sido persistentemente apresentadas no sentido contrário. Segundo, em decorrência dessa circunstância, não é possível afirmar que está havendo o esvaziamento do conceito da interseccionalidade na forma como é utilizado pelo Estado brasileiro, pois sequer há efetiva utilização nos últimos relatórios. A categoria raça, em apertada síntese, não é tomada seriamente em consideração nas medidas adotadas pelo Estado brasileiro na busca pela eficácia da CEDAW - já que os Relatórios nacionais são fonte oficial sobre as medidas adotadas pelo Estado entre os anos de 1984 e 2014.

Vale reforçar, mais uma vez, que assumir estratégias e criar diagnósticos que considere a discriminação interseccional de raça e gênero é um compromisso que o Estado brasileiro já possui em razão da ratificação da CEDAW. Dessa forma, considerar seriamente as Observações Finais e Recomendações Gerais do Comitê CEDAW, bem como, as reivindicações da Sociedade Civil como as contidas no Relatório Sombra, são medidas indispensáveis para que se tornem efetivas as disposições contidas em documentos que versam sobre os Direitos Humanos, em particular a CEDAW.

\section{Referências bibliográficas}

AKOTIRENE, Carla. O que é interseccionalidade? Belo Horizonte, Letramento, 2018.

BARDIN, Laurence. Análise de conteúdo. Lisboa, Edições 70, 1977.

CAMPBELL, Meghan. CEDAW and Women's Intersecting Identities: a Pioneering New Approach to Intersectional Discrimination. Revista Direito GV, n. 11 [2], jul-dez, 2015, pp.479-504 [https://www.scielo.br/scielo.php?pid=S1808-24322015000200479\&script=sci_abstract - acesso em: 02 de fevereiro de 2018].

CARNEIRO, Sueli. Enegrecer o feminismo: a situação da mulher negra na América Latina a partir de uma perspectiva de gênero. In: ASHOKA Empreendimentos Sociais; TAKANO Cidadania (org.). Racismos contemporâneos. Rio de Janeiro, Takano Editora, 2003, pp.49-58.

CARNEIRO, Sueli. Mulheres em movimento. Estudos Avançados, v. 17, n. 49, São Paulo, dez. 1995, pp.117132 [https://www.revistas.usp.br/eav/article/view/9948 - acesso em: 20 de novembro de 2017].

CATOIA, Cinthia de Cassia; SEVERI, Fabiana Cristina; FIRMINO, Inara Flora Cipriano. Caso "Alyne Pimentel": violência de gênero e interseccionalidades. Revista Estudos Feministas, v. 28, n. 1, Florianópolis, jun. 2020, pp.1-11 [https://periodicos.ufsc.br/index.php/ref/article/view/1806-95842020v28n160361 - acesso em: 01 de maio de 2020].

COLETIVO FEMININO PLURAL. Relatório do movimento de mulheres ao Processo de Seguimento do Sétimo Relatório Periódico Brasileiro (CEDAW/C/BRA/7 - 51 a sessão) a ser analisado no período da $57^{a}$ 
$\begin{array}{lllll}\text { Sessão } & \text { do } & \text { Comitê } & \text { Cedaw. } & \text { Dez. }\end{array}$ [http://www.tisp.jus.br/Download/Pdf/Comesp/Convencoes/CedawRelatorioAlternativo.pdf - acesso em: 11 out. 2017].

COLLINS, Patricia Hill; BILGE, Sirma. Intersectionality. Cambridge, Polity Press, 2016.

CRENSHAW, Kimberlé. Documento para o encontro de especialistas em aspectos da discriminação racial relativos ao gênero. Revista Estudos Feministas, Florianópolis, v. 10, n. 1, jan./jul. 2002, pp.171-188 [https://www.scielo.br/scielo.php?pid=S0104-026X2002000100011\&script=sci_abstract\&tlng=pt - acesso em: 01 de abril de 2015].

CRENSHAW, Kimberlé. Beyond racism and misogyny: black feminism and 2 livre crew. In: MEYERS, Diana Tietjens (org.). Feminist social thought: a reader. New York e London, Routledge, 1997, pp.246-263.

CRENSHAW, Kimberlé. Mapping the margins: intersectionality, identity politics, and violence against women of color. Stanford Law Review, v. 43, n. 6, jul. 1991, pp.1241-1299.

CRENSHAW, Kimberlé. Demarginalizing the intersection of race and sex: a black feminist critique of antidiscrimination doctrine, feminist theory and antiracist politics. The University of Chicago Legal Forum, n. 140,1989 , pp.139-167.

GIL, Antonio Carlos. Como elaborar projetos de pesquisa. 6.ed. São Paulo, Atlas, 2019.

GOMES, Nilma Lino. Alguns termos e conceitos presentes no debate sobre relações raciais no Brasil: uma breve discussão. In: BRASIL. Educação anti-racista: caminhos abertos pela lei federal $n^{\circ}$ 10.639/03. Brasília, MEC, Secretaria de educação continuada e alfabetização e diversidade, 2005, pp.39-62.

GONZALEZ, Lélia. Racismo e sexismo na cultura brasileira. Ciências Sociais Hoje, São Paulo, 1984, pp.223244.

KYRILLOS, Gabriela M. Uma análise crítica sobre os antecedentes da interseccionalidade. Revista Estudos Feministas, v. 28, n. 1, Florianópolis, 2020, pp.1-12 [https://www.scielo.br/scielo.php?pid=S0104026X2020000100204\&script=sci abstract\&tlng =pt - acesso em: 01 de junho de 2020].

LOMBARDO, Emanuela; VERLO, Mieke. Institutionalizing intersectionality in the European Union? International Feminist Journal of Politics, v. 4, n. 11, dez. 2009, pp.478-495.

MOLINA, Carmen Expositó. ¿Qué es eso de la interseccionalidade? Aproximación al tratamiento de la diversidad desde la perspectiva de género en España. Investigaciones Feministas, v. 3, 2012, pp.203-222.

ORGANIZAÇÃO das Nações Unidas. Comité para la eliminación de la discriminación contra la mujer. Grupo de trabajo anterior al período de sesiones. Respuestas a la lista de cuestiones y preguntas relativas al examen del sexto informe periódico: Brasil, 4 maio 2007 [http://docstore.ohchr.org/SelfServices/FilesHandler.ashx?enc=6QkG1d\%2fPPRiCAqhKb7yhsmPYo5NfAs NvhO7uZb6iXOTlibCT57LnVN1YE2GRJ0bZJVvRS4ibJsH4ITeKpfjkHDU6TUj3\%2bsctErOx8elunVeqh9c Hgs7XgnYRl3u4uFCQDxk4DlbD\%2fpFhSVViNKGqAw\%3d\%3d - acesso em: 9 de abril de 2018].

ORGANIZAÇÃO das Nações Unidas. Convenção sobre os Direitos da Pessoa com Deficiência. 30 mar. 2007 [http://www.planalto.gov.br/ccivil 03/_ato2007-2010/2009/decreto/d6949.htm - acesso em: 18 de nov. de 2017].

ORTIZ, Marilia. Desvendando sentidos e usos para a perspectiva de interseccionalidade nas políticas públicas brasileiras. In: Seminário Internacional Fazendo Gênero 10. Anais Eletrônicos. Florianópolis, UFSC, 2013, pp. $1-15$

[http://www.fg2013.wwc2017.eventos.dype.com.br/resources/anais/20/1386721833_ARQUIVO_MariliaOrt iz.pdf - acesso em: 30 de maio de 2016].

SCOTT, Joan W. Gênero: uma categoria útil para análise histórica. Educação \& Realidade, v. 20, n. 2, Porto Alegre, jul./dez. 1995, pp.71-99 [https://seer.ufrgs.br/index.php/educacaoerealidade/article/view/7172 acesso em: 05 de junho de 2008]. 